\title{
La cantata riberana. Música y política en historia doble de la costa de Orlando Fals Borda
}

\author{
The riberan cantata. Music and politics in double \\ history of the coast of Orlando Fals Borda
}

Jafte Dilean Robles Lomeli*

\begin{abstract}
Resumen
Realiza un paralelo entre Historia Doble de la Costa, y la vocación como compositor de música de Orlando Fals Borda. Se reconstruye la estructura musical de la cantata como instrumento hermenéutico de la realidad costeña para explorarla en los cuatro movimientos, cada uno de los cuales está dedicado a los tomos respectivos de la Historia Doble de la Costa. El tomo de Mompox y Loba como una obertura instrumental, el segundo movimiento, el del dúo Mier Nieto, donde el cúmulo de voces trata el tema de la violencia política con una melodía alerta, ruidosa, el tercer movimiento, como un coro de rebusque y aguante, resistiendo en el San Jorge, y el cuarto movimiento, la despedida de la cantata, que se representa realmente como un retorno al origen, o como lo señala bien el título de este cuarto tomo, el retorno a la tierra.
\end{abstract}

Palabras clave: cantata riberana, historia doble de la costa, música, política.

\begin{abstract}
The article makes a parallel between Double History of the Coast, and the vocation as a music composer of Orlando Fals Borda. The musical structure of the cantata is reconstructed as a hermeneutical instrument of the coastal reality to be explored in the four movements, each of which is dedicated to the respective volumes of the Double History of the Coast. The volume of Mompox and Loba as an instrumental overture. The second movement, of the duo Mier-Nieto, where the cumulus of voices deals with the theme of political violence with an alert, noisy melody. The third movement, like a chorus of rebusque and endurance, resisting in the San Jorge, and the fourth movement, the farewell of the cantata, which is really represented as a return to the origin, or as the title of this fourth volume, the return to the land.
\end{abstract}

Keywords: cantata riberana, double story of the coast, music, politics.

\section{(i) (a) (2)}

Recibido: 5 DE JUlio de 2019 | Aprobado: 6 De octubre de 2019

Cómo CITAR ESTE ARTICUlO

Robles Lomeli, J. (2020). La cantata riberana. Música y política en Historia Doble de la Costa de Orlando Fals Borda. Collectivus, Revista de Ciencias Sociales, 7(1), 37-50. DOI: https://doi.org/10.15648/Collectivus.vol7num1.2020.2530

*Doctora en Literatura y Estudios Culturales. Georgetown University. Departamento de Ciencias Sociales. Mexico. jr1424@georgetown.edu 


\section{Introducción}

Durante su autoexilio en Ginebra, Suiza en 1968 presidiendo como director de investigaciones del Instituto de las Naciones Unidas para el Desarrollo Social, Orlando Fals Borda tiene la oportunidad de colaborar con cuatro científicos sociales colombianos, Víctor Daniel Bonilla, Jorge Ucrós, Gonzalo Castillo y Augusto Libreros, en la creación de una fundación cuya meta central es "investigar para transformar" (Fals citado en Cendales et al., 2009, p.38) y que se diferencia de los antiguos trabajos del sociólogo en el tipo de acercamiento propuesto al rechazar la aplicación del positivismo funcional. Surge así, la Fundación La Rosca de Investigación y Acción Social, que se pone en práctica en 1970 en Colombia con el apoyo de la Iglesia Presbiteriana de Estados Unidos y el gobierno holandés: "Nos habíamos dividido el país, yo en la Costa Atlántica, Augusto en el Pacífico, Gonzalo en Tolima, Víctor Daniel en el sur" (Cendales et al., 2009, p.40). Fals comienza a trabajar en la Costa Atlántica en 1972, gracias a la invitación del Comité Ejecutivo de la Asociación Nacional de Usuarios Campesinos (ANUC), y es ahí donde apela a la incipiente metodología de investigación social, la IAP: Investigación Acción Participativa. Los constantes enfrentamientos entre campesinos y terratenientes ofrecen un campo fértil para el desarrollo de una metodología de investigación que se promete transformativa y afín con las necesidades de los campesinos desprotegidos hasta entonces por las facciones elitistas de la sociedad.

La invitación del Comité Ejecutivo de la ANUC conduce a Fals Borda a insertarse en la región de la Costa Atlántica por algunos años, durante los cuales participa de forma directa en la toma de tierras de los campesinos, en la lucha por una reforma agraria más justa y, sobre todo, en la convivencia diaria con la comunidad de la zona. Para 1972, los miembros de la Fundación La Rosca publican la obra Causa popular Ciencia popular donde reúnen sus experiencias en las distintas regiones de Colombia y exponen paralelamente los cimientos de la IAP. La nueva metodología acuñada por estos científicos sociales se rige por "el abandono de los recintos universitarios y la puesta en cuarentena de los marcos de referencia de la ciencia ortodoxa y parcelada transmitida por la universidad tradicional" ((Bonilla et al., 1972; Serrano, 2015; Sánchez et al., 2019). Por su nacencia extraacadémica, la IAP no se sujeta a reglas formales ni se concreta de manera permanente, se define mejor como un cuerpo flexible de ideas que emergen en el terreno y mutan en la cotidianidad vivencial.

El trabajo de La Rosca en la Costa Atlántica durante 1972 y 1974 se vio interrumpido por las discusiones internas que surgen al intentar sistematizar la IAP, algunos de los miembros participantes se quejan de no obtener resultados homólogos en todas las regiones estudiadas, de que los intelectuales se convierten en un cuadro más de lucha directa, de la escasez de estudios globales o de síntesis, y finalmente, de descuidar el contacto con otros intelectuales y el mundo universitario (Parra Escobar, 1983), todas exigencias que contradicen la metodología y que obligan a Fals Borda a retirarse en 1976 y dedicarse de lleno al propio entendimiento de la ciencia popular que se agita ante sus ojos. Tras esta fallida experiencia con La Rosca, Fals Borda permanece en la Costa Atlántica y se empeña en el esbozo del macroproyecto conocido como Historia doble de la Costa (1979-1986) donde la IAP aparece como un personaje más que acompaña a los costeños en sus cotidianas melodías y mamadas de gallo.

El compendio de cuatro tomos escrito magistralmente por Fals Borda recoge las vivencias de los riberanos de la depresión momposina y las desgaja a la vez bajo una lente colectiva compuesta por intelectuales foráneos, locales y habitantes de las laderas. La controversial -y casi ininteligible- estructura bipartita de la obra ha dado hasta la fecha mucho de qué hablar y sobre qué rodar el bolígrafo. Dividida en dos canales de información, el A lleva la anécdota y el relato, y el B carga con la interpretación teórica respectiva. Mucho se especula a propósito de esta dualidad tan distintiva, sin embargo, la perspectiva que 
aquí rescato es la del historiador Alexander Pereira, quien encuentra en el Archivo Central e Histórico de la Universidad Nacional de Colombia (ACHUNC/B), un memorándum1 de la Iglesia Presbiteriana donde Fals Borda le atribuye este montaje a la emulación polifónica de la música coral en la que era experto: “El lector podrá oír leyendo en contrapunto y armonía las voces y letanías del pueblo y el cántico de sus dirigentes mezclándose en diversas formas de estilo y presentación, incluso visual, que no puedo explicar sino como el inconsciente surgir de mi viejo amor por la música coral". Sin lugar a duda, Historia doble de la Costa puede analizarse como una cantata riberana distribuida en cuatro movimientos y codirigida por Fals Borda y habitantes locales, donde la IAP funge como pieza cohesiva entre ambos canales auditivos.

\section{La Cantata Riberana}

En la Costa colombiana los campesinos echan cuentos musicalmente y el "dejadismo" o el "dejar ser" característico de la región surge del ritmo de las aguas que a su vez da pie a los tradicionales bailes y cantos. La cultura costeña está urdida por un hilo musical que Fals Borda sólo puede interpretar mediante un acercamiento más íntimo fundado en una empatía intersubjetiva entre él y la comunidad. Sin la metodología alternativa que desarrolla en años previos esta relación sería básicamente imposible. La IAP se centra en la colaboración y por tanto en generar un nexo horizontal entre investigador e investigado.

Según los documentos que almacena el Archivo de la Universidad Nacional de Colombia en la carpeta de Documentos Personales de la Iglesia Presbiterana, Fals Borda es experto en cantatas y oratorios, especialmente aquellos de J.S. Bach. Además de sus propios elogios a este género musical religioso, se encuentran sus partituras e invitaciones a varios eventos donde él profesaba como director coral. La cantata, por tanto, es practicada en numerosas ocasiones por Fals Borda durante los años que se dedicó a la dirección coral de su Iglesia y en sus actividades universitarias extracurriculares (Pereira, 2009). De acuerdo con Prochell (1961), la cantata consiste en una "sucesión de coros, recitativos, arias y dúos con acompañamiento instrumental y que muchas veces es prologada por un trozo instrumental (Obertura)" (p.47). A las partes o secciones de una cantata se les conocen como "movimientos" (Quesada, 2016) y podría decirse que cada uno de los tomos de Historia doble de la Costa es un movimiento que se complementa con los cantos propios engendrados por los campesinos de la región en distintas circunstancias históricas y políticas. Así, la experticia musical de Fals Borda será un instrumento hermenéutico de la realidad costeña, la música del campesino un repositorio epistémico y ontológico, y la IAP el nexo comunicante de esta sintesis musical. Historia doble de la Costa es un ejercicio de colaboración musical, o bien una codirección coral, por un lado, los campesinos hacen resonar su voz y son ellos mismos quienes invitan a otros conocidos a participar en los cantos, y, por otro lado, Fals Borda trabaja en el ensamblaje atendiendo la calidad de sus voces y la pertinencia de sus experiencias. Hay un diálogo integrador entre ambos por lo que no podría suponerse una unidireccionalidad en la narración.

\subsection{Primer movimiento: El recitativo obeso}

El tomo inaugural Mompox y Loba (1979) muestra una obertura instrumental que introduce a los coreutas -campesinos- aunque éstos aún no se pronuncian, se trata de una descripción de aquello que se observa en principio. Hay aquí una pulsión más hacia lo histórico, ilustrar a las primeras familias de la región. Lo que si se deja "escuchar" es el acompañamiento instrumental de los ríos por donde bogan los intelectuales

1 ACHUNC/B. Caja 59, Carpeta 2, Doc.22-23. "Memo sobre la música sociológica”. 
locales junto con Fals Borda quienes abren la escena al atascarse cerca del puerto de Santa Coa. La imagen inicial al abrir el tomo y cubriendo ambos canales es el paisaje de la depresión momposina que sitúa al lector en esta obertura. Una vez se dan a conocer los partícipes del grupo de estudio -Juan David Cifuentes, Luis Murallas, Álvaro Mier y Ramón Pupo- se resalta la figura del recitativo, es decir, el cantor al que se le permite hablar de modo coloquial dentro de la composición musical, el poeta Candelario Obeso, que será el eje de este movimiento. El juez miembro del grupo y político Liberal, Cifuentes, cita repetidamente las canciones de bogas de Candelario Obeso, de tal manera que el poeta se convierte en un personaje más a bordo de la lancha donde navega el grupo. Candelario Obeso fue un momposino que se inspiró en los bogas para escribir sus versos. Los bogas fueron los navegantes esclavos del Río Magdalena y sus canciones surgen como una forma de protesta por la esclavitud y la explotación de la comunidad afrocaribeña. Durante los paseos forzados que tenían que realizar a través de los ríos, los bogas inventan versos y melodías con los cuales se burlan de las autoridades y sus superiores para hacer más tolerable el trayecto.

Cuando el grupo se ve obligado a desembarcar en Santa Coa visita la casa de Prudencio Vidales, un antiguo boga de la región, que les explica que "en los puertos donde había fiestas, que eran y todavía son frecuentes, los bogas nos deteníamos para bailar el bunde, el berroche o el mapalé al son de la gaita o la caña'e millo y con velas en la mano. Miren que ahora la gente no los baila como antes, con palmoteo, cantando coplas y entrando por parejas a bailar al ruedo" (Fals, 1979, p.48a). Estos festejos, estilos musicales y danzas que conoce Prudencio serán utilizados como referentes sociopolíticos en el resto de los tomos acentuando con ello la relevancia de la voz campesina en el compromiso con su propia concientización. El primer acercamiento con los habitantes de la zona evidencia el lenguaje musical empleado por ellos para agenciar históricamente su presencia en la Costa, los bailes para el boga eran un vehículo implícito de escape a su situación de opresión. El canto y la danza en el Caribe son formas de protesta colectiva que muchas veces pasan inadvertidas por los exploradores extranjeros El tipo de canciones que cubre cada tomo descubre la esencia del costeño y marca los cambios progresivos de su identidad ante los diversos embates sociopolíticos.

Simultáneamente, en el canal B, Fals (1979) denomina "proyección ideológica" a la acción de colocar a Candelario Obeso dentro del canal A, pues "aprovecha el pensamiento de este gran poeta para ilustrar la cultura negra colombiana que comenzaba a formarse en la boga de los ríos" (p.48b), el hecho de que Cifuentes y otros costeños puedan recitar sus versos de memoria indica el arraigamiento popular que posee. El recitativo se coloca en momentos específicos del primer movimiento según las elecciones del director coral, pero recurriendo a lo que los campesinos e intelectuales locales van contando y detallando al respecto. Por esta razón, no se puede hablar de una impostura directiva sino de una colaboración o codirección entre el intelectual y los habitantes de las laderas. A ambos les compete montar cada una de las secciones de la cantata riberana, a los campesinos al enunciar sus propios referentes sin recurrir a referentes externos, y a Fals Borda al recuperar estas voces y colocarlas según el modelo elegido para transmitir un determinado mensaje.

La obertura o primer movimiento entonces se compone por el recitativo de Obeso, la presentación de los rasgos de los coreutas que vienen enseguida y de los codirectores corales -Fals Borda y campesinos riberanos- con quienes se entabla la sintesis musical. La melodía instrumental de fondo se compone con el Río Magdalena, el cual va cambiando a medida que los personajes se van introduciendo, en principio es un río magnífico que trae al grupo de estudio y que guarda entre sus aguas al legendario hombre-caimán. Después las invasiones burguesas y comerciales lo transforman en una gigantesca lombriz parda llena de fango maloliente. 
El primer movimiento cumple además con la tarea de introducir a un cantor medular del lenguaje musical de la obra, Adolfo Mier Serpa, el abuelo de uno de los miembros del grupo de estudio Álvaro Mier, cuya importancia irá en crescendo en el resto de los movimientos. Aquí se echa un primer vistazo para presentarlo como músico y se muestran los instrumentos que se utilizaron en su antigua banda llamada "Once de noviembre": el bombardino y el bugle.

\subsection{Segundo movimiento: El dúo Mier-Nieto}

El segundo movimiento de la cantata El presidente Nieto (1981) se distingue por el dúo Mier-Nieto, aquí tenemos un primer coro constituido por los miembros de colegios municipales y los puestos de salud, pues mientras el grupo de estudio va caminando y hablando a la vez, se escucha un reiterativo y colectivo "iLibros sí, fusiles no!" que se une a las protestas de los cimarrones del Norosí del primer tomo, este cúmulo de voces inspira al grupo de estudio para tratar ahora el nuevo tema, la violencia política.

La melodía instrumental del río Magdalena también acompaña este movimiento, aquí aparece un río lleno de sangre: "Por eso el río Magdalena sigue siendo teatro de luchas entre hermanos. Ahora lo recorren los guardacostas, antiguerrilleros, los aviones de bombardeo y los helicópteros de reconocimiento y contrainsurgencia inspirada en Norteamérica" (Fals, 1981, p.20a). La melodía calmada que lleva a los viajeros del primer tomo y que después se oscurece con la entrada de la burguesía comercial, ahora aparece alerta, ruidosa, estruendosa, con el sonido de las hélices y las bombas. El ruido caótico acompaña a los cantores del dúo, Adolfo Mier Arias aparece en este movimiento como una composición de varias voces. A diferencia de Candelario Obeso, eje del movimiento anterior, Adolfo Mier Arias es una amalgama de varias entrevistas realizadas a algunos ancianos de la zona, no es un personaje vivo pues de serlo tendría más de 100 años. La historia de este personaje -tatarabuelo de Álvaro Mier- contrapuntea con la trayectoria política del cartagenero y expresidente Juan José Nieto, cuya voz, aunque no en primera persona, también se compone de los cuentos de sus nietos y bisnietos y de los documentos recuperados por los intelectuales locales.

El canto de Mier expone una vía no-violenta de enfrentar las guerras que acontecen en varios períodos de la historia colombiana, mientras que el canto de Nieto muestra una vía anti-caudillista de acción política. Los dos cantores serán un ejemplo del ethos no-violento de la Costa Atlántica que se busca exhibir aquí. El director aquí ensambla un dúo por medio de lo visual, además de lo vocal. En el texto, la voz de Mier aparece en márgenes más estrechos y la voz de Nieto se extiende por el contorno de las páginas, así se distinguen dos instancias narrativas. Aunque no hay una más importante que la otra, pues a pesar de que el título de esta sección se llama "El tatarabuelo a la sombra del caudillo" vemos que hacia la "Despedida" se propone una inversión en los papeles de Nieto y Mier, apareciendo Mier como la memoria colectiva y popular cuya voz se agudiza en aras de conseguir el propósito anhelado de este tomo o movimiento.

Dentro de los insumos de Mier, el campesino también elige su propio estilo musical, tal como sucede con Candelario Obeso elegido por los momposinos para enfatizar las canciones de boga, aquí Mier expone el porro paliteao. El porro también nace como canto de trabajo, así como los pescadores y navegantes crean las canciones de bogas, sólo que éste es en la tierra por las extensas sabanas de la región del Sinú (Arteaga, 1994, p.44). En este segundo tomo aparece Adolfo Mier Arias, el tatarabuelo cargando su bombardino, el mismo que Adolfo Mier Serpa muestra en el primer tomo, esto comprueba que el lenguaje musical se transmite de generación en generación, de ahí la importancia de la aparición de los nietos en el cuerpo del texto. 
De los insumos de Mier o su parte cantada del dúo se puede trazar un "mapa musical" de su movimiento y con eso ver la relevancia que tiene el porro en la vida del campesino costeño. El mejoramiento de las sabanas para la plantación del tabaco provoca que los ricos de la región hagan fiestas y berroches que exigen la creación de bandas musicales para animarlas, Adolfo Mier y su hermano Agustín Mier se enteran de esto y se trasladan hacia El Carmen para trabajar en los cultivos y unirse a una banda llamada "Arribana":

\begin{abstract}
En la banda "Arribana" de El Carmen de Bolívar, antes de Bolivar, antes de llegar nosotros, no tocaban sino valses, mazurcas, pasillos, danzas y contradanzas, aparte de las marchas de procesión que pedía el cura. El repertorio estaba escrito a notas y a mano en un libro que guardaba el director, pero todos tocaban al oído y de memoria. Con la llegada del clarinete de Agustín, la "Arribana" sufrió un sacudón, no sólo porque mi hermano sabía tocar bien las piezas, sino porque empezó a ensayar con los sonidos y a cambiar el tono del conjunto. Compuso pronto una danza de tres partes, con canto de bajo muy bonito, llamada Ramillete de flores. Agustín resultó ser un verdadero genio de la música. (Fals Borda, 1981, p.109a)
\end{abstract}

A los cantos de la procesión, considerados por los Mier como "tristes y respetuosos" decidieron mamarles gallo y le pusieron "sabor y picante" a la música con lo cual subvierten la solemnidad católica del festejo y hacen de esta fiesta algo propio, aquellos que cargan la imagen del Divino Niño empiezan a mover las caderas y levantar las paticas.La música de los Mier le imprime la esencia mamagallista del costeño a los festejos curales y religiosos, con lo cual se adueñan de los símbolos de devoción. La banda "Arribana" representa el crisol racial de la costa pues sus músicos eran descendientes de diversas culturas, por lo tanto, su producción musical no está exenta de esta mezcla:

\footnotetext{
A Agustín se le metió la fartedad de tocar aires indígenas de pito o gaita -los de os bundes- pero con el clarinete. En compañía de un timbero negro que tocaba un tambor mediado llamado porro o porrito, el bombero de nuestra banda empezó a poner la mano en el parche izquierdo del bombo y ladear la maza o voltearla para golpear la madera, repiquetear y producir golpes nuevos, contrapunteados y fuertes en el parche derecho, con el fin de reforzar el canto que llevaba Agustín en el clarinete. Yo hacía piques de apoyo y contracanto para contestar con el barítono o la trompeta. Así, entre todos, inventaos un nuevo toque endiablado al que bautizamos con el nombre del tambor: el porro paliteao. (Fals Borda, 1981, p.110a)
}

El porro no está sometido a notas, sino que se inventa sobre la marcha, “creando permanentemente la música, improvisando sabroso, sin morisquetas del director ni todo ese orden del concierto de los blancos ricos, donde todos principian y acaban juntos" (Fals Borda, 1981, p.110a). En contraposición a la música del blanco, el porro es un esfuerzo colectivo de improvisación al cual se integran técnicas e instrumentos empleados por indígenas, negros y mestizos. En la fotografía que aparece enseguida de este escenario se muestra a quien parece ser Adolfo Mier con el clarinete en la mano y a un lado una imagen de una nueva banda de Córdoba, al pie de la foto aparece la nota "El legado musical de Agustín Mier" hay aquí una yuxtaposición temporal donde se muestra el impacto que tienen personajes que ya no viven en carne y hueso pero que se transmutan en acciones actuales de los campesinos. La música es el hilo conector entre tiempo y espacio, la audacia musical de Mier nacida entre guerras se refleja ahora en la creación de bandas musicales de los jóvenes cordobeses.

Con los insumos del expresidente Juan José Nieto sucede algo similar, a pesar de que él no pertenece a ninguna banda ni se dedica a la composición musical, en algunas de sus escenas se muestra el ánimo cambiante de Nieto cuando participa en los bailes de la alta sociedad y cuando en contraste forma parte de las festividades del pueblo. La música es el medio elegido por Nieto para acortar la distancia entre él y las bases populares:

Ya había empezado a ampliar el círculo de sus contactos con las bases populares. Alejándose de los distritos amurallados de la ciudad, Juan José se vinculó a los de Ternera y el Pie de la Popa, donde se realizaban las grandes fiestas de la Virgen "mochoroca" de la Candelaria. Muchos "blancos" se escapaban a esas fiestas, dejando vacíos los bailes de salón en que quedaban las señoras, con sus arpas y flautas de aficionados. El mujeriego Juan José también se escapaba. (Fals Borda, 1981, p.47a) 
El refugio de Juan José en los festejos populares muestra su rechazo a la parafernalia de la burguesía clásica y la hipocresía de la alta esfera. En este caso la danza, la decisión de Nieto de participar en los bundes, marca radicalmente la diferencia entre él como anti-caudillo y/u otro liberal descompuesto por las presiones sociales de la hegemonía. La música que se escucha en los bailes a los que atienden los personajes marca su tendencia política, tanto que el lenguaje musical se traslada a la ideología del momento: "Se trasladó a la política la tradicional distinción cartagenera de los bailes y fiestas entre 'calzados y de casaca de lino,' por una parte, y 'descalzos' por otra. Los 'descalzos,' eran los artesanos, campesinos, negros e indios. Los 'calzados,' esto es los blancos con derecho a bailar con las mujeres de todas las razas y todos los sitios" (Fals Borda, 1981, p.118a). La actitud de Nieto en cada uno de los escenarios cambia, cuando se encuentra en los bailes de ricos, se frustra por la careta que tiene que colocarse, pero en los bundes se desvive y puede ser él mismo, sin disfraces sociales.

\subsection{Tercer movimiento: Coro de rebusque y aguante}

El tercer movimiento Resistencia en el San Jorge (1984), al igual que el segundo, muestra desorden y estertor, los campesinos pululan por doquier, aunque aquí desde adentro de la coraza de una hicotea jeguana, según la metáfora empleada por Fals Borda. Hay dos tipos de coro que surgen en este tercer tomo como resultado de las sequías e inundaciones provocados por el comportamiento de las aguas. El coro de rebusque y el del aguante, ambos se enlistan aquí como "técnicas del saber vivir y trabajar con elementos a la mano que en este caso ofrezcan el río, la ciénaga, la sabana y el bosque" (p. 25b). Durante los meses de inundación, los campesinos tienen que rebuscar por otros rumbos, como la recolección o el cultivo de otras semillas que se den en dichos ambientes, para poder sobrevivir. El aguante implica saber esperar con paciencia, más no pasividad o abulia, a que la naturaleza vuelva a proveer sus recursos. Cuando los campesinos salen de la concha de la tortuga se podría considerar la etapa de rebusque, o aquí el coro que contiene los tradicionales cantos de vaquería, pero cuando los campesinos se enroscan en su concha, se trata de un coro de aguante, donde la música es de resistencia.

Tiempo atrás cuando las aguas inundaban los potreros y los corrales de los españoles, éstos no sabían qué hacer, perdían gran parte de su ganado, no obstante, debido a la particular resistencia y rebusque del riberano, éste se adecua a las inundaciones e inventa la técnica de embalse para pasar el ganado de un lado del río al otro y evitar así su muerte. Del recorrido que realizan los campesinos durante el embalse surgen los cantos de vaquería para arrear al ganado con mayor facilidad. De no ser por las inundaciones, los cantos de vaquería resultaran innecesarios. Los zambos Julio y Lucho, miembros del coro de rebusque, cuentan a Fals Borda acerca de la técnica de embalse:

Julio espanta con su sombrero al pichón de golero que se había parado en la talanquera del corral, y lanza un grito. Los animales paran la oreja sin detener el paso. "Ahahahahquetehehehé... vaquita jé, eeé. Cuando yo tenía ganado, cantaba a la vaquería; ahora que no tengo ná, le canto a la vida mía. Ahahahahquetehehehé..." Los animales aceleran el paso. "Es que a ellos les gusta que les canten," me explica el robusto zambo puyando la espuela (Fals Borda, 1984, p.58a)

Aquí mismo, justo después del cuento de Julio y Lucho, se colocan dos fotografías de dos campesinos arriando el ganado por el camino terregoso, la imagen contribuye a esa vivacidad de la escena, es casi como si el lector pudiera escuchar el canto de vaquería mientras observa la imagen. De acuerdo con Ciro A. Quiroz (1983) la "piquería" representativa de este tipo de canto se traslada después al vallenato más comercial y conocido en el resto del país. En general esto sucede con la música caribeña que se va impregnando de ritmos, instrumentos y melodías de distintos estilos que nacen del comportamiento de las aguas o del diario trajín del campesino. La pureza, o la esencia real del Caribe y su música es la mezcla, el tejido de la hamaca y la estera. 
El coro del aguante se distingue porque sucede generalmente en espacios cerrados, o privados, y son ecos de resistencia política o cultural. El primer eco resuena el 14 de septiembre de 1785 por motivo de la fiesta del Cristo de los Milagros en la antigua villa de Ayapel. Durante la representación religiosa y en ausencia del capitán González Belandres, los campesinos comienzan a burlarse de la autoridad y provocar un desorden en la tarima de la Iglesia, por lo que el capitán de guerra encargado, el teniente Rafael Gómez decide suspender el acto. Los campesinos enojados por el abuso de poder, liderados por Evaristo y Domingo Zabaleta, se marchan hacia la casa de Manuela Guerra a armar un cangilón de bunde. El baile aquí es símbolo de rebeldía o, como expone Fals Borda en el canal B, "contrapeso político popular," a través del bunde los campesinos expresan su molestia con la autoridad y exigen ser tomados en cuenta y con mayor respeto por los capitanes de guerra. El bunde clandestino provoca una reacción intempestiva por parte del teniente: “Cuando el teniente Gómez empezó a oír el tum-tum de la tambora en medio de los truenos, mandó recado con un mozo para prohibir la fiesta por no tener el permiso de las autoridades" (Fals, 1984, p.85a). Al tum-tum del bunde le acompaña la melodía dramática de la naturaleza al soltar una tempestad sobre ellos y aumentando el estruendo con sus descargas eléctricas. Similar a la tendencia romántica del siglo XIX, la naturaleza es una aliada de los campesinos que se une a este acto de rebeldía contra la autoridad. Tras la demostración de Gómez y hartos por estos abusos, los campesinos deciden unirse y formar la "Comuna de Ayapel" para exigir un trato justo de la autoridad y hacer valer sus opiniones: "Por esta fugaz resistencia organizada y armada de la comunidad ayapeleña, se lograron ajustes perdurables en la vida colectiva y en los mecanismos del contrapeso político local ante el poder de las autoridades" (Fals, 1984, p.87a). Un bunde logra conciliar los intereses de la comunidad y sembrar en ellos la semilla de la justicia. Curiosamente, la "Comuna de Ayapel" defiende de los robos de ganado por parte de la autoridad u otros ajenos, con el temblor batiente de la tambora. La música se transforma en la alerta de peligro para los campesinos, quienes en el sonido del tambor insertan mensajes políticos y económicos.

La segunda entrada del coro se da más o menos en los mismos términos, durante la denominada guerra de "La Burrita" que en el texto se pone en voz y boca del abuelo Mier, pero que es contado en realidad por Carlos Aislanth, un antiguo líder de la resistencia campesina con quien Fals Borda conversa en la Costa. En la entrevista foliada C/OFB/GM 23 encontrada en el Centro de Documentación Regional del Banco de la República en Montería, Córdoba, Carlos Aislanth le echa el cuento a Fals Borda de lo que acontece esa noche y el impacto que un baile clandestino tendrá en la creación de las ligas campesinas de autodefensa. En el minuto 44:08 Aislanth está hablando de la intervención de su tío Francisco Serpa en la organización de las ligas: "Él no tenía idea sobre esas cosas; sino que este pueblo, Don Orlando le voy a decir, cada uno aquí ha vivido de sí, aquí no hay organización ni hay nada, ni la inventen porque no la siguen. Si usted quiere ver que el pueblo se reúna ahora, póngale una música... eso somos nosotros". El discurso de Aislanth refleja mucho de lo que el sistema dominante impone con respecto a la unión de los campesinos, para Carlos la música es un hilo conector entre ellos, pero no la considera en sí como organización política. Las autoridades ven la música como una actividad estéril cuyo poder de convocatoria tiene sólo como objetivo la bebida y el mamagallismo. Sin embargo, ambos encuentros presentados aquí permiten corroborar que la música tiene un impacto y solvencia política para el campesino.

La guerra de "La Burrita" surge por la burla musical que emprenden los campesinos contra el invasor y comerciante extranjero Mr. Cannon en San Martin de Loba, demostrando con esto que la música va mucho más allá de una reunión etílica. El coro entra con una presentación del líder de esta resistencia, Francisco Serpa, quien es descrito como un buen decimero, maestro de baile y organizador de los sainetes de carnaval, un echa cuentos especial. Los versos de Serpa se insertan en el relato de Mier: "Mister Cannon solicita/por sus amarillas, lola/De Mompox trajo a Burrita/pa'ser alcalde de Loba. // No queremos extranjeros, /dicen todos los lobanos/Queremos el pueblo solo,/ ¡Salga de aquí, mister Cannon!// Este fue el comienzo de la 
gran pelea en el pueblo entre 'cannistas' y sus opositores. Los versos de mi tío se convirtieron en himno nacional" (Fals Borda, 1984, p.175a). Gracias al ánimo que provoca la bravura y versos de Serpa, la comunidad se une y forma las Juntas de Defensa Territorial que impiden la monopolización de latifundios por la vía legal. Los versos de Serpa, convertidos en himno, se siguen cantando en todos los triunfos de las Juntas. Incluso, provocan una agitación más que traerá nuevas consecuencias organizativas para los campesinos:

\begin{abstract}
Una noche de agosto, en uno de esos merengues en casa de Josefa Próspera Serpa, el joven Antonio Centeno, quien tocaba caja, el acordeonero Sebastián Guerra y otro que raspaba la guarachaca se pusieron a cantar "Mister Cannon solicita" y "No queremos extranjeros", en el ritmo que hoy forma parte del vallenato. El alcalde que los oye, se viene derechito al baile con su bastón de mando de cacho enlazado, vestido de blanco y con los anteojos puestos, con tres agentes de policía. (Fals Borda, 1984, p.178a)
\end{abstract}

De nuevo, al igual que en Ayapel, la autoridad se molesta con la música y la burla de los campesinos e intercede violentamente a poner fin a sus festejos. En esta ocasión, la gente comienza a rezongar y al verse Centeno apoyado por los gritos de la comunidad "levanta la caja de currulao que tocaba, se la manda al alcalde por la cabeza" (ob. Cit) mientras que el acordeonero Sebastián improvisa una pulla contra la autoridad y la gente responde con alegría armándose un gran jolgorio. La escena podría considerarse un tono alto dentro del coro que resalta con mayor intensidad, el lector puede oír leyendo el relajo del pueblo. Sin mencionar que, la caja o el tambor de currulao de Centeno funciona como un arma física contra el alcalde, mientras que el acordeón de Sebastián es un arma ideológica. Los instrumentos musicales adoptan también un rol político de defensa campesina. Más adelante en la escena, Francisco Serpa y Carlos Aislanth se unen al baile clandestino e improvisado lo cual incita aún más la frustración del alcalde y sus policías, hacia el final, los lobanos ganan la guerra de La Burrita pues las autoridades se dan por vencidas y se retiran de ahí. La bulla y las pullas de los coreutas llega a cristalizarse luego en la organización de ligas campesinas de defensa, lideradas por Serpa y Aislanth. En estos coros, los coreutas son configurados por sus habilidades musicales, en el caso de Julio y Lucho por entonar los cantos de vaquería necesarios para arriar el ganado al otro lado del río, y en el caso de los hermanos Zabaleta o los miembros de la familia Serpa, por unirse a bailes clandestinos e improvisar versos contra los extranjeros y las autoridades.

\title{
2.4. Cuarto movimiento: La despedida y el retorno
}

En el cuarto movimiento Retorno a la tierra (1986) encontramos la despedida de la cantata, que en realidad es un retorno al origen. En la despedida interviene el dúo de Francisco Velázquez y la conquistadora Francisca Baptista enmarcado por el coro de voces campesinas, así como también un aria de Fals Borda con la inserción de sus notas de campo. La primera mención musical de este movimiento viene de la boca del "capi" Ferias con quien Fals Borda conversa al inicio de su recorrido por el resguardo indígena de San Andrés de Sotavento. La visita del codirector de la cantata coincide con una "cumbiamba" que tiene lugar en el resguardo y a la cual es invitado a participar. Mientras el "capi" le echa cuentos acerca del pasado indígena y las costumbres que poco prevalecen en la actualidad, la cumbiamba resuena de fondo y después es utilizada como un ejemplo de las nuevas generaciones indígenas que reniegan de su pasado y contribuyen al olvido de sus raíces. El "capi" dice que los jóvenes ya no se interesan por la cumbiamba indígena porque "se habían acostumbrado a las ortofónicas primero (con el dedo), luego a los ruidosos 'picós' del casco del pueblo con sus discos de corridos mexicanos y paseos vallenatos" (Fals Borda, 1986, p.23a). El gusto musical elegido por los jóvenes determina su identidad y la postura que ocupan con respecto a la interpretación histórica de su cultura. Si los jóvenes aprenden a bailar la cumbiamba entonces estrechan lazos más sólidos con sus antepasados, según el propio "capi," quien después les aconseja: "Aprendan a bailar la cumbia, muchachos, si no quieren pagar impuestos" (ob. Cit), la comunidad indígena no paga impuestos, 
por ende, si los jóvenes aprenden la música y las tradiciones serán identificados políticamente como tal, esto se convierte en una opción de solvencia económica. A este primer anuncio de la importancia primaria que tiene la música para los indígenas y campesinos de la zona, se suma el dúo de Franciscos y los coreutas Juana Conde y José Latiniano Sánchez.

El dúo, así como aquel de Adolfo Mier y Juan José Nieto en el segundo movimiento, se identifica por los márgenes de los informes. La primera voz, expuesta en el margen más ancho, corresponde a la Conquistadora Baptista cuya trayectoria por las sabanas es narrada en tercera persona. Se podría decir que por la cobertura de los márgenes y el tipo de información que aparece, la voz de la Conquistadora es más aguda y cobra mayor relevancia. La voz de Francisco Velázquez, también en tercera persona, se coloca en los márgenes más estrechos. El contrapunto aquí resalta las diferencias entre ambos en relación con la conquista de territorios y el trato con otras personas. La Conquistadora es más respetada que Francisco y además encumbra el ethos no-violento de la comunidad, mientras que la actitud de Francisco se emparenta más con la venganza, lo despótico y la soberbia. Si en el dúo de Mier y Nieto se percibe un paralelismo entre ellos y un acompañamiento vocal donde ninguno sobresale, aquí si hay una distinción entre la gravedad vocal del hombre y la agudeza de la mujer. A través de este contraste, el codirector va desarrollado el concepto de "mujer brava" que rige el movimiento completo. Por otro lado, el dúo se enmarca con el coro compuesto por algunos campesinos, predominantemente Juana Conde y su nieto Latiniano.

A pesar de que la información que se coloca en voz de Juana Conde, anciana de la región, proviene en realidad de las cartas redactadas por José Latiniano y sus entrevistas con Fals Borda, se elige resaltar la voz de la mujer. La motivación para esto puede ser dual, a saber, se busca mantener o fortalecer el concepto de "mujer brava" que se escucha en primer plano de voz de la Conquistadora. 0 bien, se enfatiza la importancia del "chozno" y la transmisión de cuentos de generación en generación como se expuso antes. En una de las cartas de José Latiniano² encontrada en el Centro de Documentación de Montería, en la página 1 se describen las características del fandango "cantao," que es muy similar a la acción que desempeñan Francisco y la Conquistadora. Se dice del fandango que "para esta modalidad el conjunto consistía en un tambor, una cantadora, o cantador, o los dos juntos para echarse piques, para echarse vainas o puyas, acompañando con las palmas," tal parece que los Franciscos no sólo están cantando sus verdades a dueto, sino que también están danzando al son del fandango mientras recitan sus versos piqueros. El coro de Juana Conde y Latiniano enmarca el dúo de los conquistadores otorgando interpretaciones posibles para sus acciones y siendo un reflejo de la actualidad, es decir, hay de nuevo una yuxtaposición de pasado y presente cuyo hilo conductor es el lenguaje musical. Conde y Latiniano analizan el pasado de la conquista utilizando el molde natural del fandango, la confrontación entre Franciscos se explica mediante un esquema musical que el campesino conoce a la perfección. Por esta razón se dice que, Fals Borda no importa modelos extranjeros para explicar la realidad de la Costa, sino que los sustrae del mismo medio y las vivencias que atraviesa. El campesino se auto-explica con la colaboración del intelectual gracias a esta sintesis musical.

En este cuarto movimiento también se puede trazar un mapa económico de la región por medio de los ritmos y estilos musicales que surgen de las diversas labores, por ejemplo, los tabacaleros de El Carmen y Ovejas impulsan el fandango y las bandas de viento ya que cuentan con el poder colectivo que surge de la migración. Los habitantes de otros pueblos migran a las sabanas por el auge del tabaco trayendo consigo sus propios estilos musicales que se combinan aquí para crear algo nuevo y único de esa zona y de ese oficio:

2 Caja 05 Carpeta 02 Folios 1773-1782. La carta se titula "Festejos de pascua y año nuevo en algunos pueblos del bajo Sinú en tiempos pasados." 
[El fandango y las bandas de viento] Desde mediados del siglo pasado se arraigaron también en el Sinú, donde hallaron compositores geniales, cantadoras, copleros, decimeros y bailadoras que impusieron su estilo en el arte; al alternar la música con el trabajo agrícola tejiendo entre sí ambas actividades y enriqueciéndolas, estas personas se recuerdan y admiran todavía entre los más grandes personeros del pueblo costeño. (1986, p.122A)

Las amalgamas musicales evidencian los puntos donde la migración es más intensa o donde los oficios tienden a ser más redituables. Esto a su vez habla del comportamiento de la naturaleza en cada región, puesto que si existen condiciones favorables para la siembra de tabaco eso causará una mayor producción lo que detonará la migración, a mayor número de migrantes se puede decir que las condiciones del año han sido positivas. Los oficios de los campesinos se configuran según el estilo que nazca del tejido músicalabor, no olvidemos, por ejemplo, las canciones de los bogas que se originan a las orillas del río por los pescadores o en los recorridos en barcos por sus navegantes transportistas.

Dentro del coro de este movimiento vuelve a aparecer el coreuta Adolfo Mier Arias, el tatarabuelo, para anunciar una fusión musical más. El texto se refiere al origen de este tipo de canción/baile como un "milagro" que sucede cuando el hermano del tatarabuelo Mier "cambió la gaita por el clarinete para interpretar las mismas melodías, dando nacimiento al fandango tapao instrumental que después se llamó 'porro sabanero'." Este estilo, gracias a los recorridos no-violentos de los Mier y la transmisión de generación en generación, va desde El Carmen, Corozal y las sabanas a través del Chinú, Purísima, Lorica, Sabanal y Ciénaga de Oro hasta nuestros días (Fals Borda, 1986, p.126A-127A). Fals Borda titula "Los embrujos del Sinú" al capítulo de este cuarto tomo donde se mencionan algunas de las mezclas musicales más trascendentes de la identidad cultural costeña. La música, en los cuatro movimientos de la cantata riberana, es un embrujo que une a todos aquellos que escuchen cualquiera de los estilos musicales enunciados aquí. De hecho, muchas de las escenas se enmarcan también con inclusiones musicales, en ocasiones el grupo de estudio o el propio Fals Borda son interrumpidos por la música que parece embrujarlos y transportarlos por distintos períodos históricos, además de hilar a los campesinos, la música yuxtapone fases históricas.

Las inserciones musicales en este movimiento se dan de dos maneras, con versos de cantantes locales conocidos por el pueblo y poetas regionales con los cuales Fals Borda conecta la información al gesto rítmico del campesino. Pero también con el uso de simbología musical dentro de la narración, en una de las escenas donde un pájaro mayero canta y los campesinos deciden musicalizarlo aparece el diálogo que entablan entre ellos por medio de pentagramas:

\footnotetext{
Un mayero [...] vino a engarzarse en un roble de flores moradas y empezó a cantar el paso de la tropa. Alejandro Ramírez se detuvo: 'Oigamos a ese mayero, que nos quiere decir algo más que anunciarnos el agua como lo hace cada año,' pensó. [Pentagrama del canto del pájaro] 'Pongámosle música,' propuso, y empezó a imitar el canto del pájaro con el clarinete, tal como lo habría hecho un indio con la gaita cabeza'e cera. Y le añadió como contestación propia, mientras proseguía la marcha: [Pentagrama del clarinete de Ramírez] A los primeros e inseguros intentos del clarinete de Alejandro, Primo Paternina se sumó ahí mismo con el cornetín reforzando la melodía con agudas notas: [Pentagrama del cornetín de Primo Paternina] Enseguida ensayó Pablo Garcés el bombardino, oyendo los acordes especiales: [Pentagrama del bombardino de Pablo Garcés] Y Saturnino el bombo: [Nota musical del bombo de Saturnino]. (Fals Borda, 1986, p.129A)
}

Del diálogo anterior se pueden analizar varios puntos, en primera instancia, que el lenguaje musical es también comunicación natural, el pájaro canta para dar a conocer que se aproximan las lluvias, los campesinos interpretan su realidad musicalmente, si se escuchan cantos de vaquería hay inundaciones, si se escuchan pájaros mayeros hay lluvias, si se escucha el alboroto de un bunde algún triunfo se celebra. La naturaleza cuenta con su propia música y su simbología, el pájaro mayero se integra al diálogo campesino en este juego de pentagramas. Por otro lado, prueba que la música de Caribe colombiano nace de la improvisación, la necesidad, el trabajo y se constituye como un ejercicio colectivo donde cada uno de los campesinos con su instrumento va sumándose para construir una melodía multipersonal: "Prosiguieron 
el camino hacia La Madera 'sacando' el nuevo porro 'El pájaro del monte' paso a paso y conjuntamente, sumando y combinando los instrumentos como un diálogo y contrapunteo, sin que se pudiera decir quién fue el compositor porque lo fueron todos en un singular acto de creación colectiva" (ob. Cit). El lenguaje musical rompe la jerarquía vertical característica de los grupos dominantes, en el ejercicio colectivo los campesinos aprenden a compartir su autoridad. La esencia musical de colaboración y generosidad autorial distingue también al codirector Fals Borda, quien integra la cantata a los estilos propios de los costeños para generar un producto colectivo novedoso, una síntesis cultural que potencializa la trasformación y la toma de conciencia sociohistórica de ambos.

La próxima vez que aparece un pentagrama dentro de la narración en este tomo es en la escena que introduce a la heroína musical de este movimiento, María Barilla, cuyo porro predilecto es precisamente el del pájaro mayero compuesto por Ramírez, Paternina, Garcés y Saturnino (Fals, 1986, p.137a). El fandango, anunciado por Latiniano, Juana Conde y Adolfo Mier, es un "espectáculo comunal de baile nocturno al aire libre," (Fals, 1986, p.131b) en el que Barilla es famosa por su participación y al cual le debe su reputación como "mujer liberada, sin los prejuicios y mojigaterías de la sociedad" (Fals, 1986, p.133a). La técnica de baile emprendida por Barilla enaltece su figura como una "mujer brava" que no se deja imponer el estilo de los hombres y que es capaz de elegir sus propios pasos y griticos. Según Fals Borda, María Barilla potencializa con sus acciones en el baile y la política un ambiente "despreocupado y alegre, tolerante y comprensivo de la Montería de principios de siglo" (Fals, 1986, p.134a).

La libertad que exhibe la danzante en la impresión de un estilo propio al fandango y la oportunidad que tiene de participar en los fandangos que celebran la libertad de las provincias en eventos patrióticos la colocan en la cima de la admiración campesina. Fals Borda en este punto de la cantata vuelve al rol de "mujer brava" en la emulación narrativa de un fandango pasiao, pues aparece Barilla rodeada de hombres que desean bailar con ella, pero ella decide con quién, cuándo, dónde y hasta qué momento lo hace. El contraste entre hombres y mujeres en este cuarto movimiento y la exposición de la bravura y resistencia de la mujer costeña simboliza la contraparte no-violenta del capitalismo. Particularmente en esta entrega, el capitalismo violento, vengativo y arrasador viene siempre de la mano de algún hombre que olvida o ignora sus valores costeños, mientras que la mujer encarna una actitud más comunal, generosa, comprensiva y tolerante con la sociedad. Además de tomar la batuta en el baile, la mujer lleva las riendas de la familia, la redención social y la política.

Después del alboroto de los últimos movimientos, viene una melodía mucho más tranquila que puede considerarse ese retorno a la tierra o al origen. La inserción de las notas de campo del codirector coral corresponde al aria o la sección solista de la cantata. Después de recorrer todos los movimientos de la cantata y los ritmos colectivos de los campesinos costeños, el codirector integra su experiencia total a la reevaluación de sus notas, por lo tanto, el adiós es más bien una toma de conciencia musical que evidencia que el solista no está realmente solo, pues es un ser renovado por la actividad comunal.

En esta metáfora, las notas de campo de Fals Borda de sus años previos a la escritura de Historia doble de la Costa se colocan para ser recompuestas, por eso se habla de un retorno al origen. Aquí la IAP adquiere también nuevos matices. La experiencia total de Fals Borda durante la redacción de los cuatro tomos le sirve para autoanalizarse como intelectual, académico e investigador, como si el propio campesino le hubiera dado la oportunidad de estudiarse a sí mismo. Este quizás sea el clímax de la colaboración y la síntesis musical, cuando el investigar cede también a ser investigado por el otro. 


\section{Conclusión}

A manera de conclusión, la maquetación de Historia doble de la Costa es una síntesis del lenguaje musical de ambos, el intelectual como codirector de una cantata con sus cuatro movimientos y los campesinos como coreutas protagonistas de la cantata con sus propios ritmos, estilos y tradiciones. Cada uno de los tomos contiene elementos musicales propios del Caribe colombiano que reflejan las conductas, oficios y actitudes de los campesinos, y a la vez, los comportamientos de la naturaleza, como el canto del pájaro mayero o los subibajas de las aguas. Si el intelectual o investigador elige la estructura de la cantata y las intervenciones de los coreutas, son los propios coreutas o campesinos quienes enuncian su lenguaje musical, de ahí esta síntesis que se propone. El conocimiento de Fals Borda y de los campesinos se dialoga y se une para inducir una comprensión mutua y una concientización dual hacia la transformación de la sociedad. La cantata riberana pudiera ser una alegoría de lo que idealmente se visualiza como proyecto político y sociológico, no se trata de cambiar radicalmente la situación de la Costa o asumir que la cultura popular por si misma logre transformar la sociedad, pero brinda un ejemplo de cómo la IAP puede aplicarse para subvertir las relaciones de poder existentes y encaminar hacia una repartición más justa de los bienes y derechos fundamentales del ser humano. La música es un vehículo de aproximación que brinda la IAP para comprender epistemologías alternativas, transformar antiguos esquemas y modelos académicos y colaborar con las comunidades hacia el bienestar social.

\section{Referencias bibliográficas}

Arteaga, J. (1994). Música del Caribe. Colombia: Editorial Voluntad.

Bonilla, V. D., Castillo, G., Fals Borda, O., \& Libreros, A. (1972). Causa popular, ciencia popular. Una metodología del conocimiento científico a través de la acción. Bogota: La Rosca.

Cendales, L., Torres, F., \& Torres, A. (2009). Uno siembra la semilla, pero ella tiene su propia dinámica. Orlando Fals Borda o la Democracia Radical (en memoria 1925-2008). Maestras y maestros gestores de nuevos caminos. Cuadernillo, (49), 12-54.

Fals Borda, O. (1979). Historia doble de la Costa: Mompox y Loba. Bogota: Carlos Valencia Editores.

Fals Borda, O. (1981). Historia doble de la Costa: El presidente Nieto. Bogota: Carlos Valencia Editores.

Fals Borda, O. (1984). Historia doble de la Costa: Resistencia en el San Jorge. Bogota: Carlos Valencia Editores.

Fals Borda, O. (1986). Historia doble de la Costa: Retorno a la tierra. Bogota: Carlos Valencia Editores.

María, C., \& Procheli, A. (1961). El protestantismo, su música y sus músicos. Revista musical chilena, 15(77), 39-51. Retrieved from https://revistamusicalchilena.uchile.cl/index.php/RMCH/article/view/16080

Parra Escobar, E. (1983). La investigación-acción en la Costa Atlántica: evaluación de la Rosca, 1972-1974. Cali: Fundación para la Comunicación Popular.

Pereira Fernández, A. (2009). Orlando Fals Borda: la travesía romántica de la sociología en Colombia. Revista Latinoamericana de Ciencias Sociales, 1(2), 211-247.

Quesada Gutiérrez, M. (2017). Cantata para orquesta sinfónica y coro ‘Espacio me has vencido. Retrieved from http://dspace.ucuenca.edu.ec/handle/123456789/27076 
Quiroz, C. (1983). Vallenato, Hombre y Canto. Bogota: İcaro.

Sanchez Fernández, S., Pérez de Guzmán, V., Rebolledo Gámez, T., y Rodríguez Casado, R. (2019). La cultura de paz y conflictos: implicaciones socioeducativas. Collectivus, Revista de Ciencias Sociales, 6(1), 265-285. https://doi.org/10.15648/coll.1.2019.13

Serrano, Y. (2015). El Estado en Cuba. Reflexiones en torno a su encargo social en relación con las familias. Collectivus, Revista de Ciencias Sociales, 2(2), 74-100. https://doi.org/10.15648/coll.2.2015.5 